\title{
Cercos para las ideas: el acceso al conocimiento bajo amenaza
}

\author{
CLAUDIO GUTIÉRREZ G. ${ }^{1}$
}

1. Departamento de Ciencias de la Computación, Facultad de Ciencias Físicas y Matemáticas, Universidad de Chile.

El pensamiento occidental distingue tradicionalmente dos esferas en el mundo del ser humano: lo material y lo espiritual. Una dice relación con la naturaleza y las interacciones con ella, y el otro, con asuntos que son propiamente producto del "espíritu”, la esfera del intelecto, donde pertenece el conocimiento ${ }^{1}$. Dado que los recursos naturales son escasos y costosamente reproducibles (el multiplicar bienes materiales -e.g. pan, peces- ha llegado a ser caracterizado como don divino), no es sorprendente que los mecanismos de su apropiación definan buena parte de los conflictos de la historia humana.

Algo muy diferente había ocurrido desde siempre con el mundo inmaterial. Se asumía que los productos intelectuales eran un bien común (la lengua, las leyendas, los ritos, etc.). Tardíamente, con el advenimiento de la sociedad mercantil, comenzó a aparecer el tema de la propiedad privada de ciertos productos intelectuales, como textos, música, técnicas, etc. Gradualmente prosperó esta tendencia, hasta que hoy -en gran parte debido a las nuevas tecnologías digitales- el tema ha hecho crisis, y asistimos a un punto de inflexión respecto del estatuto de los bienes inmateriales, en particular del conocimiento. Ha surgido, por primera vez en la historia de la humanidad, el peligro del cercamiento (prohibición de libre acceso) al conocimiento que generamos como humanidad.

En lo que sigue presentamos los antecedentes básicos para entender este fenómeno, enfatizando las iniciativas de quienes luchan por frenar esta tendencia y mantener abierto el mundo del conocimiento.

El objetivo de este artículo es presentar el movimiento por el acceso libre al conocimiento que se ha venido generando en las ultimas décadas, y entregar antecedentes básicos para iniciar una discusión local sobre sus implicancias y alcances.

\section{Conocimiento y poder}

"El presidente en Washington nos comunica que desea comprar nuestras tierras. Pero, ¿cómo se puede comprar el cielo?, ¿la tierra?. La idea es desconocida para nosotros. Si no somos dueños de la frescura del aire y del centelleo del agua, ¿cómo pueden comprarlas?”.

Este discurso atribuido al jefe indio Seattle, refleja bien el proceso de "cercamiento" de los bienes públicos materiales que ha experimentado la sociedad occidental ${ }^{2}$. Los argumentos

${ }^{1}$ Gran parte de lo que expondré aquí refiere a conocimiento científico, esto es, “conjunto de conocimientos obtenidos mediante la observación y el razonamiento, sistemáticamente estructurados y de los que se deducen principios y leyes generales” (RAE). Pero el planteamiento se extiende a las producciones intelectuales del ser humano.

${ }^{2}$ Aunque es consenso entre los historiadores que la atribución al jefe Seattle por H. Smith en 1873 es apócrifa, el texto refleja muy bien las posiciones de un agudo y sensible observador de mediados de siglo XIX.

Correspondencia a:

Claudio Gutiérrez G.

E-mail: cgutierr@dcc.uchile.cl 
-inspirados en la experiencia inglesa con los nativos en norteamérica- van en dos frentes: el estatus de los bienes públicos ${ }^{3}$, esto es, ¿'son derechos ancestrales? ¿están sujetos al derecho de propiedad privada? etc.; y la retórica del despilfarro, del desperdicio de recursos que, administrados de manera "eficiente" producirán mejores frutos. En particular, un argumento clave para justificar la concentración de la propiedad es el de las “economías de escala”. Uno de los ideólogos del nuevo orden capitalista, John Locke, justicaba así el despojo de los labradores de sus derechos ancestrales sobre la pastura, la caza y la recolección de leña y frutos en espacios comunes: "nada fue hecho por Dios para que el hombre lo malaproveche o destruya"; sólo aquel "industrioso y racional" merece títulos ${ }^{4}$.

El proceso de cercamiento de los bienes públicos intelectuales es mucho más reciente. Sus orígenes pueden remontarse a la toma de conciencia del valor (poder) que tiene el conocimiento. Un primer hito ocurre alrededor del siglo XVII, cuando la ciencia comienza a transformarse, desde una actividad meramente contemplativa, poco sistemática, reducida a individualidades o salones aristocráticos, en una actividad organizada, institucionalizada, con fines “prácticos” enlazados con la producción, los gobiernos y el mundo material. Como escriba Francis Bacon en 1620, a quien usualmente se invoca como uno de los inspiradores de este proceso, "hay que abrir para el entendimiento humano un camino enteramente diferente de lo conocido y proveerle otras ayudas, para que la mente pueda ejercer sobre la naturaleza de las cosas la autoridad que propiamente le pertenece"5. La mente ejerciendo autoridad sobre la naturaleza... otra época nacía.

Esta nueva mentalidad se expresa en el florecimiento de academias y sociedades científicas, los primeros journals, la instituciona- lización de la investigación científica en las universidades y su difusión de la ciencia a través del sistema educacional. Los modelos universitarios napoleónico y de Humbolt reflejan esta preocupación por el cultivo sistemático del conocimiento como parte esencial de las tareas de una nación. Comienza a ser claro que el conocimiento científico es fundamental en la economía y el poderío de las personas, las instituciones, las empresas y las naciones.

Las trazas de esto en nuestro país se aprecian claramente en la discusión sobre educación. Escribía Darío Salas en 1917:

"El adelanto de nuestro país se liga, sin duda, al aprovechamiento de las riquezas naturales de nuestro suelo; pero se halla más estrechamente vinculado todavía al aprovechamiento de nuestra energía humana. Los recursos de hombres son menos abundantes y más valiosos que los recursos naturales; [...] Y entre nosotros, son precisamente los recursos de hombres lo que más se desperdicia. Porque es energía humana lo que se malgasta cuando dejamos en la ignorancia a medio millón de niños y a más de un millón de adultos y adolescentes" $"$

Sin embargo, no es sino en los últimos cincuenta años que esa tendencia larvada explota. Los economistas asocian crecimiento económico con el conocimiento; la composición de la masa laboral se sesga hacia el sector de servicios, finanzas, marketing, educación, tecnologías de información e industria cultural; hay cambios profundos en las formas de generación y difusión del conocimiento. Un factor que cruza todo esto es el desarrollo de nuevas tecnologías, particularmente la informática y las comunicaciones. El fenómeno es reconocido transversalmente: sociólogos como Manuel Castells hablan de "sociedad del conocimiento"; economistas del Banco Mundial refieren al "conocimiento como fundamento del desa-

\footnotetext{
${ }^{3}$ Bien Público (según RAE): "El de los bienes destinados al uso publico, como las plazas, los caminos o el litoral; a un servicio público, como los edificios públicos o los puertos; o cuya concesión compete a la Administración, como las minas o las aguas continentales. Su régimen jurídico implica la propiedad de una administración pública y un sistema propio de uso y protección”.

${ }^{4}$ Citado en: H. Travis, Pirates of the Information Infrastructure: Blackstonian Copyright and the First Amendment, Berkeley Technology Law Journal, Vol. 15: 777-863, 2000.

${ }^{5}$ Francis Bacon, The Great Instauration, Preface. 1620.

${ }^{6}$ Darío Salas, El Problema Nacional, Edit. Universitaria, 1967 (original 1917).
} 
rrollo"; gurús empresariales como Peter Drucker hablan de "economía del conocimiento"7.

Es así que la creación de conocimiento, que alguna vez tuvo un sesgo desinteresado y un aura de neutralidad, comienza a vivir un cambio radical. La idea de libertad del conocimiento sufre la presión de la utilidad, el mercado y el control político ${ }^{8}$. Probablemente la transformación del Banco Mundial en un "Banco de Conocimiento" es lo que mejor refleja este profundo giro, donde simbólicamente el conocimiento toma el lugar del dinero como fuente del poder. Su reporte 1998-99 sostiene que "el conocimiento, no el capital, es la clave para un crecimiento económico sostenido y mejoras en el bienestar humano"9.

\section{Cercos para el conocimiento}

A medida que el conocimiento se convertía en fuente de poder, surge la tensión entre su apropiación privada y su carácter de bien público. Hay dos aristas que nos interesaran en este artículo: el copyright y las patentes ${ }^{10}$.

La ley chilena define la patente como "un derecho exclusivo que concede el Estado para proteger una invención”. Para que se otorgue una patente, la invención debe cumplir con tres requisitos: "Ser novedosa, tener nivel inventivo, ser susceptible de aplicación industrial”. Luego en principio no se otorgan patentes por ideas abstractas, fórmulas matemáticas, leyes de la naturaleza, procesos mentales.

Una de los primeros sistemas de patentes surgió en la Venecia del siglo XV con la idea de incentivar a los inventores a poner sus ideas en aplicación sin temor a que se las copiaran. Se pedía que el aparato fuese original; que estuviera probada su utilidad; y se otorgaba una protección de varios años (diez) y se indicaban penas a quienes infringieran la patente. En 1624 se establece en Inglaterra el sistema de patentes industriales, cuya motivación es el incentivo a la producción, que puede considerarse la inspiración de los sistemas actuales.

En esta tensión entre el bien público y la propiedad privada, hay dos áreas que recientemente han suscitado enconados debates en el mundo de las patentes: el software y la vida. El software es el paradigma de la codificación de procedimientos y un gran sector industrial vive de el. Como tradicionalmente no se pueden patentar fórmulas ni algoritmos (por ejemplo, si se patentara el método de división clásico, cada vez que Ud. hace una cuenta debiera pagar un derecho por ello), esto ha producido gigantescas presiones por parte de la industria del software sobre los límites de lo patentable. El debate es profundo y agitado ${ }^{11}$. El caso de la vida es más complejo aún. La primera patente sobre la vida, una bacteria, es de 1980. Esto abrió la puerta para el patentamiento de semillas (Monsanto habla de "piratería de semillas”"12), y luego de material genético. Al igual que el software, esto ha provocado un acalorado debate sobre los límites de la patentabilidad ${ }^{13}$.

En el mundo de la salud, las patentes inciden en drogas, genéricos, equipos, software, etc. Hay una creciente preocupación sobre el rol de las patentes en la investigación biomédica, y críticas a la apreciación tradicional que las patentes incentivan la innovación y la

\footnotetext{
${ }^{7}$ Manuel Castells, La Era de la Información (volumen 1): economía, sociedad y cultura. La Sociedad Red. Editorial Alianza (2005). Banco Mundial, Knowledge for Development (K4D). Peter Drucker, The Age of Discontinuity: Guidelines to Our Changing Society, 1969. Cap. 12.

${ }^{8}$ M. Peters, Higher Education, Globalization and The Knowledge Economy: Reclaiming the Cultural Mission, Ubiquity, 8, Issue 18, May 8, 2007 - May 14, 2007.

${ }^{9}$ World Development Report Publicado en 1998 por World Bank; Oxford University Press USA. Para una visión crítica de este proceso: Lyla Mehta, The World Bank and Its Emerging Knowledge Empire. Human Organization, Vol. 60, No. 2, 2001.

${ }^{10}$ La propiedad intelectual tiene mas facetas: Marcas, diseños, indicaciones geográficas, modelos, denominaciones de origen, etc.

${ }^{11}$ R. Stallman, Fighting software patents, http://www.gnu.org/philosophy/fighting-software-patents.html Ver también: http:// www.ffii.org/

${ }^{12}$ Center for Food Safety, Monsanto versus U.S. Farmers, 2005. http://www.centerforfoodsafety.org/pubs/CFSMOnsantovsFarmerReport1.13.05.pdf

${ }^{13}$ Daniel J. Kevles. From Eugenics to Patents: Genetics, Law, and Human Rights. Annals of Human Genetics 2011; 75: 326-33.
} 
reinversión en investigación y desarrollo. Por otro lado, se acusa al sistema actual de patentes de dificultar a los investigadores el acceso a materiales y métodos patentados; de poner en riesgo cuidados médicos por los precios de medicinas esenciales (como antivirales) en países pobres ${ }^{14}$.

El copyright (derechos de copia) es el mecanismo legal que permite a los creadores mantener la propiedad exclusiva de sus obras por un tiempo fijo. La motivación original era el incentivo a compartir los productos del trabajo intelectual (arte, música, escritos) al conjunto de la sociedad ("sacarlos" de la oscuridad de la mente individual o del manuscrito personal), esto es, enriquecer la cultura universal. Aunque también pueden buscarse trazas antiguas de este procedimiento (Venecia, siglo XV), usualmente se señala el año 1710 y la ley inglesa como la inspiración de la legislación posterior.

Es importante señalar que más que los creadores, los principales impulsores e interesados en el copyright han sido tradicionalmente las casas editoriales y las industrias culturales ${ }^{15}$. Sus argumentos para el monopolio editorial han variado desde la necesidad de censura, pasando por supuestos derechos naturales, hasta el de despilfarro y desperdicio de recursos y la necesidad de economías de escala. No son muy diferentes de los que vimos para el cercamiento de los bienes materiales.

La presión de estos grupos puede verse en la legislación norteamericana. El Copyright Act de 1790 daba 14 años (aproximadamente una generación) más una extensión de otros 14 si era pedida por su autor. Esto es la obra quedaba en dominio público en no más de 28 años. En 1831 fue modificada -a petición del editor Webster- a 28 años más 14, que ahora podían “cobrar” los descendientes del autor. En 1909 se subió a 28 iniciales más 28 de extensión. En 1976, se extendió a la vida del autor más 50 años de extensión, y 75 en el caso que los derechos pertenecieran a una corporación, en forma retroactiva. En 1998, finalmente, los plazos se extendieron por 20 años, y a 120 en el caso de corporaciones. El lector ya imaginara quien estaba detrás de estas extensiones: no por casualidad se le llama Ley Sony Bono o Ley Mickey Mouse... ${ }^{16}$.

Sólo digamos para finalizar esta sección que la implicaciones de los terminos de co- $^{-}$ pyright pueden verse en el área de la salud en el costo de los textos y manuales, el acceso a publicaciones científicas, y en todo material reproducible.

\section{Hacia el libre acceso}

No es difícil ver que este asimilar, reducir, los objetos intelectuales a los materiales, para así aplicarles la lógica de la mercancía privada, tiene serios inconvenientes. Como veíamos antes, estamos frente a un cambio de época. Y es que la economía del conocimiento destruye los paradigmas anteriores. Frente a la esencial escasez y limitación de bienes materiales, el conocimiento es abundante e ilimitado. Contrariamente al dinero y los bienes materiales, el conocimiento crece y se enriquece cuando se comparte. No respeta cercas locales ni fronteras nacionales, y es imposible "materializar" su encierro territorial. Su valor depende fuertemente del contexto, de quien lo usa: el significado de un conjunto de bits es su interpretación. Finalmente, el conocimiento está (aun) íntimamente enganchado con el ser humano:

\footnotetext{
${ }^{14}$ Gold ER, Kaplan W, Orbinski J, Harland-Logan S, N-Marandi S (2009) Are Patents Impeding Medical Care and Innovation? PLoS Med 7 (1): e1000208.doi:10.1371/journal.pmed.1000208

${ }^{15}$ Los creadores que viven de su obra son la excepciÓn. En Chile por ejemplo, los poetas Mistral, Neruda, Huidobro, de Rokha, y Parra, necesitaron siempre trabajar para vivir. Sus "contratos” con las casas editoriales se reducían a lograr que su obra fuese difundida, recibiendo porcentajes miserables de las entradas que ella generaba a la editorial. Después de muertos (los cuatro primeros), fundaciones y editoriales se han hecho millonarias con su obra. ¿Les sirvió el copyright de incentivo a la creación? Ni que hablar de poetas menores.

${ }^{16}$ cf. Travis, op. cit., pp. 815-7.

${ }^{17}$ Si llegara la época en que las máquinas reemplacen a la creación humana, como reemplazaron la fuerza y varias habilidades humanas, es un asunto muy debatible. En este aspecto, aún son muy relevantes las disquisiciones del creador de los computadores, Alan Turing, en su artículo Computing Machinery and Intelligence. Mind, 59: 433-60 (disponible abiertamente en la Web).
} 
no aparece sencillo prescindir de sus creadores, o "automatizar" a los creadores ${ }^{17}$.

Ocurre que, similar al impacto que provocó la imprenta sobre la difusión de los escritos, las facilidades de codificación de procedimientos (software) y de reproducción digital de música, imágenes, textos, etc. han provocado una revolución en la universalización del conocimiento. Como lo sostiene la declaración de Berlín sobre acceso abierto firmado por más de cien universidades, institutos de investigación, agencias de financiamiento, fundaciones, bibliotecas y sociedades científicas y profesionales europeas: "La Internet ha cambiado fundamentalmente las realidades prácticas y económicas relacionadas con la distribución del conocimiento científico y el patrimonio cultural. Por primera vez en todos los tiempos, la Internet nos ofrece la oportunidad de construir esa representación global e interactiva del conocimiento humano, incluyendo el patrimonio cultural y la perspectiva de acceso mundial. [...] Nuestra misión de diseminar el conocimiento será incompleta si la información no es puesta a disposición de la sociedad de manera expedita y amplia. Es necesario apoyar las nuevas posibilidades de diseminación del conocimiento, no sólo a través de la manera clásica, sino también utilizando el paradigma del acceso abierto por medio de Internet”"

Sin embargo, las grandes industrias culturales parecen ignorar los nuevos tiempos tecnológicos e intentan cerrar este campo: restringiendo o monitoreando los bits en Internet; prohibiendo la reproducción de material digital; prohibiendo el compartir material digital; poniendo increíbles, costosas y artificiales trabas a la copia de productos de software; extendiendo leyes de copyright y patentes en forma escandalosa. etc.

Hoy, sin embargo, a diferencia de lo que le ocurrió a los labradores pobres en Europa y a los nativos norteamericanos, han surgido comunidades organizadas con mucho impacto que se han propuesto defender los bienes públicos virtuales.

Probablemente quienes iniciaron este gran movimiento en pro del conocimiento como bien público fue la comunidad del software libre, que ha inspirado gran parte del pensamiento sobre el rol de la propiedad intelectual en la era de las TIC. Piénsese en procedimientos médicos, y su posible codificación en un programa computacional. Uno esperaría al menos tener las siguientes libertades básicas ${ }^{19}$ :

1. Ejecutar el programa, para cualquier propósito.

2. Estudiar como trabaja el programa, y cambiarlo para que haga lo que usted quiera. El acceso al código fuente es una condición necesaria para ello.

3. Redistribuir copias para que pueda ayudar al prójimo.

4. Distribuir copias de sus versiones modificadas a terceros. Si lo hace, puede dar a toda la comunidad una oportunidad de beneficiarse de sus cambios. El acceso al código fuente es una condición necesaria para ello.

Los partidarios del software libre han sido criticados por tener un modelo de desarrollo muy restrictivo. Otro grupo de partidarios del software libre y GNU/Linux tomó una filosofía ligeramente diferente, permitiendo modelos de negocios más amigables para la industria, y menos "ideológico" respecto de su competencia con el software propietario. Crearon así la noción de Open Source, basada en las nociones de acceso al código fuente y redistribución libre, siguiendo algunos criterios básicos ${ }^{20}$.

No se trata sólo de programas. También de información y fuentes de datos. Open Data es un movimiento en pro de la publicación de datos e información en forma abierta, esto es, sin restricciones de copyright. Ha tomado fuerza con las políticas de transparencia de gobiernos

\footnotetext{
${ }^{18}$ Declaración de Berlín sobre acceso abierto, 22 octubre de 2003. http://mpg.de/index.html Es bueno precisar que la revolución no la ha provocado solo Internet (la red física mundial), sino la Web, que es la capa lógica sobre Internet que permitió crear un espacio universal de información.

${ }^{19}$ R. Stallman, Por qué el software no debe tener propietarios. Stallman fundó en 1985 la Free Software Foundation, http:// www.fsf.org/

${ }^{20}$ Ver http://www.opensource.org/, “Open Source Definition”. Para una lúcida exposición de su filosofía, ver el artículo de uno de sus fundadores, Eric Raymond, The Cathedral and the Bazaar (1997-2001).
} 
y las organizaciones académicas que crecientemente ponen sus datos e información en forma abierta en línea.

Hay otro movimiento que propugna el libre acceso no sólo a datos e información, sino también a todos los bienes culturales. Open Access es un movimiento para permitir el acceso libre a fuentes de información, conocimiento y cultura. Hay muchas organizaciones que la impulsan, desde consorcios de universidades, de editoriales, organizaciones de académicos, etc ${ }^{21}$.

Todas estas iniciativas han comenzado a sistematizarse y ser llevadas al mundo real para el ciudadano común a partir del lanzamiento de Creative Commons. Hasta hace poco, para un creador no había más opción para cautelar la difusión de su obra y sus derechos, que optar por un copyright o dejarla sin copyright (en ambos casos, con los riesgos que terceros -inescrupulosos o incluso parientes- pudieran eventualmente "cerrarla” al acceso público y comercializarla). Y así, de pasada, restringir su modelo de negocios a "negociar" con una casa editorial u otra industria cultural (En el caso de los científicos e investigadores, cederles los derechos a las casas editoriales científicas; en el caso de autores, entregar sus derechos a cambio de la difusión). Creative Commons es "una organización sin fines de lucro, que permite compartir y usar la creatividad y el conocimiento a través de herramientas legales abiertas”. Provee un sistema de licenciamiento de obras simple y estandarizado, para permitir poner tus obras en el dominio público. En una frase, permite pasar de "todos los derechos reservados" (del copyright clásico) al "algunos derechos reservados" 22 .

\section{El caso de la salud}

Las réplicas para el campo de la salud son inmediatas. Por un lado, se comienza a tomar conciencia del rol de los creadores: "Los contribuyentes pagan por la mayoría de la investigación medica y clínica medica en los Estados Unidos y en los países desarrollados. Entonces, ¿quién es el dueño de los resultados de esa investigación? Los contribuyentes, obviamente". Pero resulta que los resultados son apropiados por revistas, editoriales que luego venden esa información a la comunidad médica, que a su vez los prorratea a los pacientes. Luego, los dueños de esa información deben pagar de nuevo ${ }^{23}$. Hay muchas experiencias que están siguiendo las políticas de acceso abierto: Medscape, PubMed Central, Free Medical Journals, BioMed Central, the Public Library of Science/Medicine, Open Medicine.

Por otro, se evidencian las asimetrías en el acceso al conocimiento -muchas veces crucial para salvar vidas- entre grupos, pases y regiones con diferentes niveles económicos y sociales. En el área farmacéutica, hay diversas iniciativas en esta dirección: La tropical disease initiative, el Institute for One World Health; Drugs for Neglected Diseases initiative; la fundación Open Source Drug Discovery, que intentar imitar modelos similares a las practicas Open Source en el mundo del software.

\section{A modo de conclusión}

Estamos viviendo tiempos "interesantes" en la esfera de los bienes públicos virtuales y las luchas en torno a su estatus. El advenimiento de Internet y la Web permite hoy generar nuevos modelos de acceso al, y difusión del, conocimiento, impensables antes, que ponen en tela de juicio los métodos tradicionales de protección/incentivos industriales e intelectuales.

Hemos expuesto las posiciones y métodos de quienes abogan por lograr que el conocimiento se mantenga efectivamente como un

\footnotetext{
${ }^{21}$ Para una visión actualizada de las diferentes organizaciones que han surgido en esta dirección, busque en Wikipedia las palabras “Open Access”. Según la UNESCO, “Open access es la provisión de acceso libre a información revisada por pares del ámbito académico y de investigación. Prevee que el dueño de los derechos de derechos universales e irrevocables de acceso a copiar, usar, distribuir, transmitir y hacer trabajos derivados en cualquier formato y para cualquier actividad legal con adecuada atribución al original”. Open Access to Scientic Information and Research, UNESCO. www.unesco.org/webworld/en/ openaccess y su portal www.unesco.org/ci/goap

${ }^{22}$ Creative Commons, http://creativecommons.org/

${ }^{23}$ George Lundber, Editor Jefe de MedGenMed. “Open Access Medical Publishing Is Finally Coming Alive”. MedGenMed 2005; 7 (3): 55. http://www.ncbi.nlm.nih. gov/pmc/articles/PMC1681691/
} 
bien público, al alcance de todos los habitantes del planeta. Creemos que ello permitirá incentivar la creación cultural y el conocimiento científico, bienes públicos intrínsicamente sociales $^{24}$.

Es importante destacar que es un movimiento donde cada persona y cada organización tiene mucho que decir y hacer. Una de las cosas que ha develado la Web es que todos somos creadores, cada cual aportando con su grano de arena a conformar la cultura universal ${ }^{25}$.
Es una tarea de todos aportar y promover el libre acceso al conocimiento. Partiendo por dejar públicamente accesible nuestra experiencia, nuestros artículos, nuestras clases, los datos de nuestras investigaciones. Siguiendo por incentivar a nuestras comunidades y a nuestras organizaciones a hacerlo. Finalmente, oponiéndose a quienes intentan cercar el libre acceso la creación intelectual.

Las futuras generaciones nos lo agradecerán.

\footnotetext{
${ }^{24}$ Sobre esto recomiendo ver la serie de videos Everything is a remix, http://www.everythingisaremix.info/watch-the-series/

${ }^{25}$ La producción de conocimiento científico también ha cambiado acordemente. Ver por ej. H. Nowotny, P. Scott, M. Gibbons, 'Mode 2’ Revisited: The New Production of Knowledge. Minerva 2003; 41: 179-94.
} 